\title{
Factors associated with HPV vaccination uptake in Uganda: a multi-level analysis
}

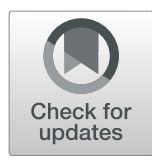

Alone Isabirye*, Martin Mbonye, John Bosco Asiimwe and Betty Kwagala

\begin{abstract}
Background: The cervical cancer burden in Uganda is high amidst low uptake of HPV vaccination. Identification of individual and community factors associated with HPV vaccination are imperative for directed interventions. Conversely, in most Low and Middle Income Countries (LMICS) including Uganda this problem has not been sufficiently studied as the influence of individual and contextual determinants remains undetermined in spite of their substantial effect on HPV vaccine uptake. The aim of the study was to identify individual (school attendance status, age of girls, ethnicity, and amount of media exposure) and community (socioeconomic disadvantages) factors associated with HPV vaccination.

Methods: Based on a modified conceptual framework for health care utilization, hierarchical modelling was used to study 6093 girls, aged 10-14 years (level 1), nested within 686 communities (level 2) in Uganda by analyzing data from the 2016 Uganda Demographic and Health Survey.

Results: Majority (78\%) of the girls had not been vaccinated. A number of both individual and community factors were significantly associated with HPV vaccination. The Odds of HPV vaccination were higher among girls age; 11, 13, and 14 compared to girls age 10 years, attending school compared to girls not attending school, who were; foreigners, Iteso, Karamajong, Banyoro, Basoga, and other tribe compared to Baganda, living in families with 1-8 members compared to those living in families with 9 or more members and middle social economic status compared to poor wealth quintile.

Conclusions: Both individual and community factors show a noticeable effect on HPV vaccination. If higher vaccination rates are to be achieved in Uganda, these factors should be addressed. Strategies aimed at reaching younger girls, street children, out of school girls, and girls with lower SES should be embraced in order to achieve high vaccination uptake.
\end{abstract}

Keywords: Human papilloma virus, HPV, Vaccine, Multilevel analysis, Uganda

\section{Background}

Worldwide, cervical cancer is the fourth most common type of cancer with 528,000 new cases annually, after lung cancer (583,100 cases), colorectal cancer (614304), and breast cancer $(1,676,633$ cases) [1]. Cervical cancer is responsible for 266,000 deaths among women worldwide [1]. However, the disease disproportionately affects

\footnotetext{
* Correspondence: aloneisab@gmail.com
Department of Population Studies, School of Statistics and Planning, College

* Correspondence: aloneisab@gmail.com
Department of Population Studies, School of Statistics and Planning, College of Business and Management Sciences, Makerere University, Kampala, Uganda
}

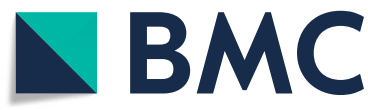

(c) The Author(s). 2020 Open Access This article is licensed under a Creative Commons Attribution 4.0 International License, which permits use, sharing, adaptation, distribution and reproduction in any medium or format, as long as you give appropriate credit to the original author(s) and the source, provide a link to the Creative Commons licence, and indicate if changes were made. The images or other third party material in this article are included in the article's Creative Commons licence, unless indicated otherwise in a credit line to the material. If material is not included in the article's Creative Commons licence and your intended use is not permitted by statutory regulation or exceeds the permitted use, you will need to obtain permission directly from the copyright holder. To view a copy of this licence, visit http://creativecommons.org/licenses/by/4.0/. The Creative Commons Public Domain Dedication waiver (http://creativecommons.org/publicdomain/zero/1.0/) applies to the data made available in this article, unless otherwise stated in a credit line to the data.

women in limited-resource countries; almost $70 \%$ of the global burden occurs in areas with low or medium levels of human development [1]. Globally, cervical cancer is the most common cancer among women in 39 of the 184 countries and is the principal cause of cancer mortality among women in 45 countries, including Uganda. These are mainly developing countries [2]. The 20112020 Global Vaccine Action Plan declared a decade of vaccines vision where member states were challenged to ensure 90 and $80 \%$ national and district HPV vaccine coverage respectively by 2020 [3]. The 2013 World 
Cancer Declaration encouraged member states to ensure universal vaccination against HPV [4]. Additionally, goal three of the Sustainable Development Goals (SDGs) calls upon member states to reduce premature mortality from non-communicable diseases by one-third through prevention and treatment [5].

Sub-Saharan Africa has the third highest incidence (17.5\%) of cervical cancer cases after India (17.7\%) and East and Central Asia (18.2\%). The region shares the second largest number of global cervical cancer deaths (21.6\%) after India (25.4\%). It is the only region where cervical cancer is equivalent to breast cancer with each constituting a quarter of the global cancer burden $[2,6]$. In Sub-Saharan Africa, the East African region registers the highest number of new cervical cancer cases (52613) [7].

Uganda is among the five countries with the highest cervical cancer incidence rates in the world. It is the most commonly diagnosed cancer and has the highest incidence of malignancy and mortality among women [8]. The country's age-standardized incidence rate of 47.5 per 100,000 is more than three times the global estimate and the country's age-standardized mortality rate of 25 per 100,000 is more than four folds the global estimate of 6.8 per 100,000 [9]. Estimates in Uganda show that approximately 3500 women are newly diagnosed and 2400 die from cervical cancer each year. Eight out of every 10 women at the Uganda Cancer Institute are suffering from cervical cancer. Projections show that by 2025, about 6400 new cervical cancer cases and 4300 deaths will occur annually in Uganda [9].

Majority of the cervical cancer cases are potentially preventable. World Health Organization (WHO) and Uganda's Ministry of Health $(\mathrm{MOH})$ recognize primary prevention of cervical cancer i.e. preventing the initial onset of cervical cancer by vaccinating girls aged 9-14 years before exposure to sex/ HPV as a very important factor in the prevention of cervical cancer [10-12]. In 2006, the United States Food and Drug Administration (FDA) approved Gardasil; a vaccine that prevents infection with the two high-risk strains of Human Papilloma Virus (HPV) (HPV 16 and 18) recognized to cause around $70 \%$ of cervical cancers [11]. Studies have proved the cost-effectiveness of the HPV vaccine [13-15].

In Uganda, HPV vaccines against HPV 16 and 18 have been available since 2006 [16]. The first HPV pilot vaccination in Uganda was first implemented in 2008 in Nakasongola and Ibanda districts to assess the feasibility of the intervention. It was later piloted in 12 other districts in 2012 [17]. The breakthrough of these pilot projects paved the way for a countrywide rollout of the HPV vaccination in November 2015 [18]. The Ministry of Health through its strategic plan for cervical cancer prevention committed itself to achieving 80\% HPV vaccine coverage among eligible girls [12]. Existing cross sectional evidence for Lira district has established low coverage (17.4\%) of HPV vaccination [19] pointing to the urgent need to establish the predictors of HPV vaccine uptake.

A number of studies have examined the predictors of HPV vaccination [19-23]. Most of these studies are mainly from developed economies. Schooling status [19, 22], being older [20, 21, 23], ethnicity [20, 24, 25], medium social economic status [21, 23, 25] were significantly associated with HPV vaccination. These studies focused on the associations between individual-level factors and HPV vaccination with an assumption of independence of errors which is partly realistic. They did not segregate the effect of individual and community factors on HPV vaccination even when they dealt with data of hierarchical nature. Most of those previous studies overlooked the significance of contextual phenomena since community-level determinants were not appropriately considered in their analyses. It is important to put contextual phenomena into consideration as people dwelling in the same neighborhood tend to exhibit similarities with respect to their health outcomes. For that reason, it isessential to consider contextual factors either at the design and/or analytical phase to understanding individual health outcomes in a population. In Low and Middle Income Countries (LMICs), HPV vaccination is yet to be sufficiently examined by multilevel analysis, an analytic approach that takes care of both random and fixed effects in a single model. Multilevel analysis facilitated us to detach the effect of individual and community factors on HPV vaccination based on the level at which they shaped HPV vaccination. In contrast, the deployment of single-level analyses (individual or ecological analyses) instead of multilevel analyses presents challenges in inferring whether community-level determinants affect HPV vaccination uptake notwithstanding the individual factors or whether inter-community variation in HPV vaccination is entirely influenced by individual characteristics without any influence of community-level determinants. Additionally, there is growing evidence of associations between communitylevel factors and HPV vaccination after considering individual factors [26]. The present study seeks to investigate whether HPV vaccination can be predicted by personal and community determinants using a multi-level model.

\section{Methods}

The study used secondary data from the 2016 Uganda Demographic and Health Survey (UDHS). Permission to access the UDHS data was sought from Measure DHS [27]. The UDHS employed a cross-sectional survey that applied a stratified two-stage cluster sampling design [28], which was used in the 2014 population and housing census [29]. A comprehensive explanation of sampling approach is published in the UDHS report [28]. The 2016 UDHS household members' recode contains 
data of 91,167 household members age $0-98$ years. We selected girls age 10-14 years who were eligible for HPV vaccination module and the household respondent answered the question "has (name) ever had HPV Vaccine to prevent cancer?". This resulted into a weighted sample of 6093 girls [27].

\section{Measure of outcome variable}

The outcome variable "HPV vaccination" was measured using the question: "has (name) ever had HPV Vaccine to prevent cancer?" (No/Yes). This question was asked eligible household respondents who were parents or guardians of girls age 10 to 14 years.

\section{Explanatory variables}

Individual and community characteristics that were examined for possible associations with HPV vaccination were based on a framework with components adapted from Anderson -Newman behavioral model of health services utilization and Bandura's social cognitive theory $[30,31]$. This framework was developed taking into account the available information in the 2016 Uganda Demographic and Health Survey. The adapted framework for HPV vaccination is depicted in Fig. 1.

\section{Individual-level determinants}

Individual-level variables included girls' age [10-14], currently attending school (Yes/ No), ethnicity (Baganda,
Foreigners, Luo, Lugbara, Iteso, Karamajong, Banyankole, Banyoro, Basoga, and Others), region (Western, Central, Eastern, Karamoja, and Northern), sex of household head (Female/ Male), number of members in the household (18 and $\geq 9$ members), relationship to the household head (daughter and other relationship) and living with mother in the household (No/ Yes). Access to media was assessed using amount of media exposure. Amount of media exposure was obtained using data on a households' ownership of media types such as televisions, radios, and telephones. For this study, amount of media exposure was categorized into 0,1 , and $\geq 2$ types of media.

\section{Community level determinants}

The community (cluster) was used as the primary sampling unit (PSU) of the data. The community influence on HPV vaccination was measured by considering the socioeconomic status of the community in which the girls were living. The community socio-economic disadvantage was operationalized by combining two factors: place of residence (rural/urban) and wealth index (poorest, poorer, middle, and rich quintile). These variables were obtained by combining individual answers for each question to the cluster (community) level. The Principal Component Analysis (PCA) was used to generate community wealth quintiles. A number of studies have applied community wealth quintile as a community-level determinant $[32,33]$.

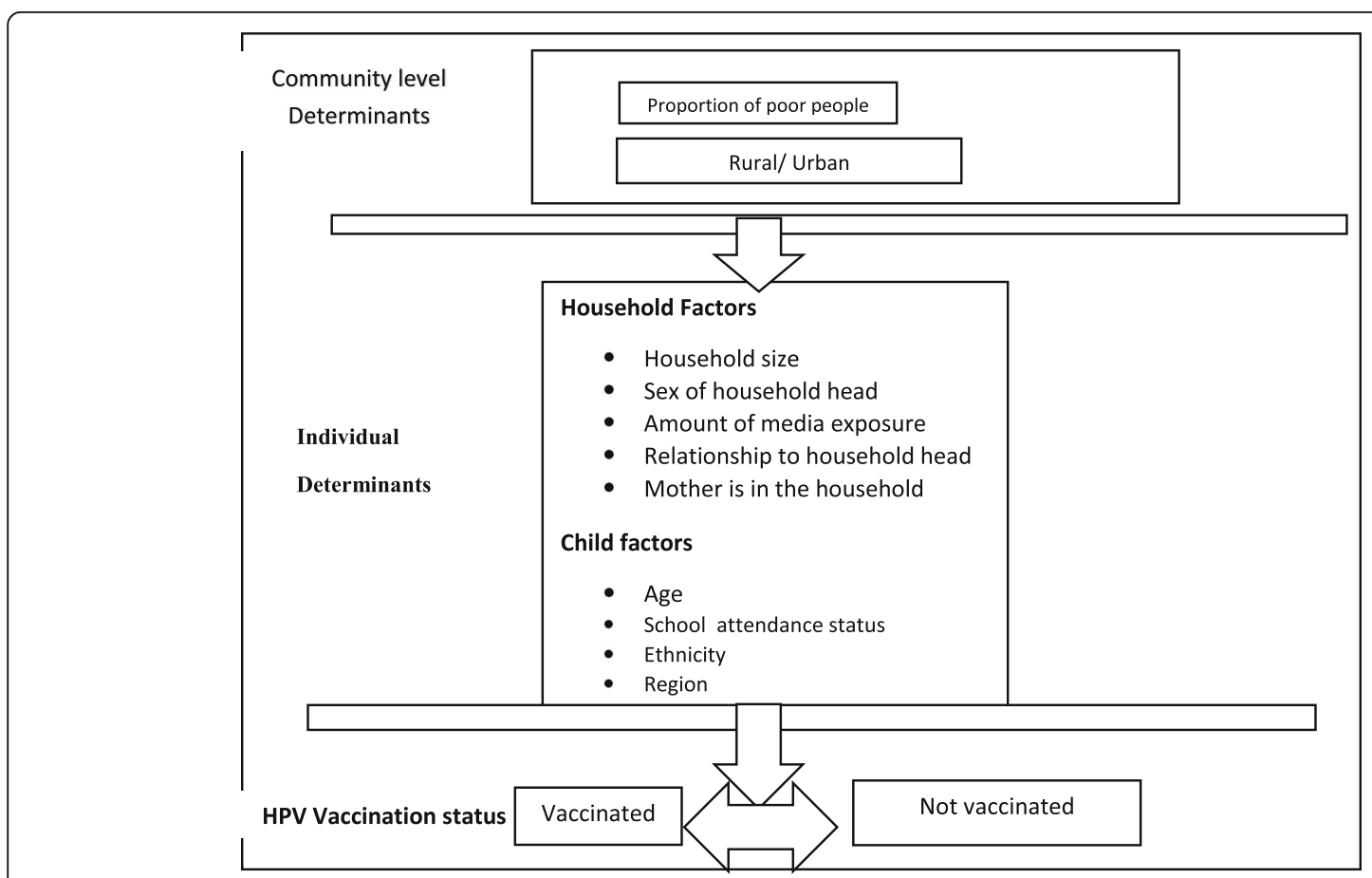

Fig. 1 Conceptual Framework for individual and community-level determinants influencing HPV vaccination 


\section{Statistical analyses}

We used frequency distributions to describe the demographic and socioeconomic characteristics of the girls. Associations of individual and community level characteristics with HPV vaccination (predicted variable) were investigated using cross-tabulations. We used Pearson's chi-squared $\left(x^{2}\right)$ tests to examine the independent predictors of HPV Vaccination and the level of statistical significance was set at $p<0.05$. Data analysis was guided by the framework for health care utilization and the hierarchical nature of the Uganda DHS data. Thus, we used the three-step multi-variable multilevel logistic regression with the log-binomial function of the generalized linear mixed models family [34]. The associations of individual-level and community-level determinants with HPV vaccination were analyzed in a stepwise manner. The nesting of individual-level determinants within community-level determinants in which girls live generated three models for analysis. We started by fitting the variance component model or empty model (null model); the empty model excluded the fixed effects. The variance component model was constructed to determine whether the variation in HPV vaccination could be explained by variations in communities in which girls live (model including random effects only). This was attained by establishing the Intra-Cluster Correlation coefficients (ICCs)/ Variance Partition Coefficients. The ICCs are obtained by dividing the proportion of variance at the group level with the total variances at the individual and group levels [35]. We fitted model 2 adding all the individual-level factors. Finally, model 3 was fitted comprising of individual-level and community-level determinants. To assess the fitness of model 3 relative to model 2, we estimated the likelihood ratio test and Akaike Information Criterion (AIC) of the two models; with a lower AIC value denoting a better model fit [36]. The odds of HPV vaccination while controlling for individual-level and community-level determinants in model 3 were presented with their accompanying $P$ values and 95\% confidence intervals [37]. We performed Variance Inflation Factor (VIF) and Tolerance test to check for multicollinearity among the covariates in the models. No multicollinearity problems were observed in the regression models since all variance inflation factor values were less than 10 and tolerance values were greater than 0.1. Stata SE 15 software was deployed for the analyses and the two-tailed Wald test was used to determine the statistical significance of the covariates at significance level of alpha equal to 5\% [35].

\section{Ethical considerations}

All data that was used in the study were obtained from the 2016 UDHS. During data collection, written informed consent was obtained from each respondent before the interviews [28]. We obtained approval to use the data from the DHS repository (http://dhsprogram. com/data/available-datasets.cfm).

\section{Results \\ Descriptive characteristics}

The general characteristics of the study population are shown in Table 1 . About $74 \%$ of the girls were below 13 years, 1 in three $(30.5 \%)$ were from the Eastern region and a larger proportion (82.9\%) were from rural areas. Approximately a quarter $(24.9 \%)$ of the girls were in the wealth quintile of poorest. Most of the girls (89.9\%) were attending school. The majority were living in male headed households (66.6\%) with 5-8 household members $(59.5 \%)$. The majority lived in households with access to media (90.9\%). Majority (69.6\%) were daughters to household heads and were living with their mothers (66.6\%). More than two thirds (78\%) (results not shown in Table 1) had not received the HPV vaccine.

\section{Association of Individual-level and Community level characteristics with HPV vaccination}

Table 1 shows the findings of the cross tabulation (Chisquare tests) of individual and community explanatory variables with $\mathrm{HPV}$ vaccination. HPV vaccination was significantly associated with the age of girls, region, schooling status, relationship to household head, number of household members, and ethnicity. HPV vaccination was higher among girls age 13 years $(23.8 \%)$, in Karamoja region (23.8\%), girls who were attending school (22.7\%), and those who were living with their mothers in the household (22.9\%). It was also relatively high among girls who were daughters to the household head (22.8\%). Vaccination was high among girls who lived in households with 2 or more types of media (22.6\%) and with less than 8 members (22.7\%). HPV vaccination was relatively high among foreigners (34.6\%). Type of place of residence, sex of household head, disability status, amount of media exposure, and wealth index were not significantly associated with HPV vaccination.

The results of multi-level analysis are presented in Table 2. The null model (empty model) which is also referred to as variance component model (results not shown in Table 2) was used to determine the total variance in HPV vaccination that is due to the communities in which the girls were living. There was significant $(P$ value $<0.001)$ variation in HPV vaccination at community-level. The study findings show that community-level determinants partly account for the total variance in HPV vaccination hence the community-level determinants were sufficiently catered for by the Multivariable Multilevel Regression Analysis (MMLRA). Our variance partition coefficient (VPC) or 
Table 1 Distribution of girls by their demographics, socioeconomic factors and HPV vaccination $(N=6093)$

\begin{tabular}{|c|c|c|c|c|}
\hline Characteristic & $\%$ OF GIRLS & Frequency & (\%)Vaccinated & $P$-value \\
\hline \multicolumn{5}{|l|}{ Age } \\
\hline 10 & 24.7 & 1504 & 19.5 & 0.034 \\
\hline 11 & 16.8 & 1023 & 23.4 & \\
\hline 12 & 21.7 & 1322 & 21.1 & \\
\hline 13 & 20.9 & 1271 & 23.8 & \\
\hline 14 & 16.0 & 973 & 23.3 & \\
\hline Region & & & & 0.010 \\
\hline Kampala & 3.3 & 203 & 18.2 & \\
\hline Central & 14.0 & 854 & 18.2 & \\
\hline East & 30.5 & 1859 & 22.6 & \\
\hline Karamoja & 5.7 & 349 & 28.9 & \\
\hline North & 21.9 & 1332 & 22.4 & \\
\hline West & 24.6 & 1496 & 20.3 & \\
\hline \multicolumn{2}{|l|}{ Type of residence } & & & 0.482 \\
\hline Urban & 17.7 & 1040 & 21.1 & \\
\hline Rural & 82.9 & 5053 & 22.1 & \\
\hline \multicolumn{2}{|c|}{ Currently attending school } & & & $<0.0001$ \\
\hline No & 10.1 & 617 & 15.1 & \\
\hline Yes & 89.9 & 1246 & 22.7 & \\
\hline \multicolumn{2}{|c|}{ Sex of household head } & & & 0.117 \\
\hline Male & 66.6 & 4057 & 21.5 & \\
\hline Female & 33.4 & 2036 & 23.0 & \\
\hline \multicolumn{2}{|l|}{ Has disability } & & & 0.246 \\
\hline No & 97.1 & 5914 & 22.1 & \\
\hline Yes & 2.9 & 179 & 18.4 & \\
\hline \multicolumn{2}{|c|}{ Relationship to household head } & & & 0.016 \\
\hline Daughter & 69.6 & 4242 & 22.8 & \\
\hline Other relationship & 30.4 & 1851 & 20.0 & \\
\hline \multicolumn{2}{|c|}{ Amount of media exposure } & & & 0.447 \\
\hline 0 & 19.2 & 1168 & 21.4 & \\
\hline 1 & 51.4 & 1961 & 21.3 & \\
\hline$\geq 2$ & 29.4 & 2964 & 22.6 & \\
\hline \multicolumn{2}{|c|}{ Mother is in the household } & & & 0.017 \\
\hline No & 33.4 & 2036 & 20.2 & \\
\hline Yes & 66.6 & 4057 & 22.9 & \\
\hline \multicolumn{2}{|c|}{ Number of household members } & & & 0.028 \\
\hline $1-8$ & 74.4 & 4532 & 22.7 & \\
\hline $9+$ & 25.6 & 1561 & 20.0 & \\
\hline \multicolumn{2}{|l|}{ Wealth index } & & & 0.243 \\
\hline Poorest & 24.9 & 1516 & 21.1 & \\
\hline Poorer & 20.4 & 1243 & 20.8 & \\
\hline Middle & 21.2 & 1290 & 23.7 & \\
\hline Rich & 33.4 & 2044 & 22.3 & \\
\hline
\end{tabular}


Table 1 Distribution of girls by their demographics, socioeconomic factors and HPV vaccination ( $N=6093)$ (Continued)

\begin{tabular}{llll}
\hline Characteristic & \% OF GIRLS & Frequency & (\%)Vaccinated \\
\hline Ethnicity & & & \\
Foreigners & 0.9 & 55 & 34.6 \\
Baganda & 13.4 & 814 & 19.7 \\
Luo & 18.2 & 1110 & 21.9 \\
Lugbara & 4.6 & 281 & 21.4 \\
Ateso & 9.0 & 550 & 23.8 \\
Karamajong & 4.5 & 275 & 30.6 \\
Banyankole & 15.1 & 917 & 16.7 \\
Banyoro & 5.7 & 350 & 24.9 \\
Basoga & 6.3 & 384 & 27.3 \\
Other & 22.3 & 1357 & 21.9 \\
\hline
\end{tabular}

intra-cluster correlation (ICC) of 0.56 indicate that the communities in which the girls live contribute to $56 \%$ of the variation in HPV vaccination. This also suggests that the intra-community correlation amongst girls vis-à-vis the likelihood of HPV vaccination was 0.56 .

The estimated community variance was also presented as median odds ratios $(\mathrm{MOR}=0.24)$ which means that girls from an average community in Uganda had $24 \%$ less odds of having already been vaccinated. After the decomposition of HPV vaccination in model 1, level one fixed effects (individual-level covariates) were added into the empty model to form model 2 . The community-level variance increased in model 2 which means that the frequency of individual factors is different in all communities in Uganda. After considering both individual and community-level characteristics in model 3 , it was observed that the community-level variance reduced marginally in model 3 . This showed that the frequency of community factors is almost similar in all communities in Uganda. After the addition of both individual and community-level factors, the variation in HPV vaccination behavior among communities remained significant. The estimated ICC show that the variability (54\%) in HPV vaccination was due to community differences (ICC $=0.54, P<0.0001)$. It is worthy to state that a random intercept model was considered rather than the usual single-level model due to the hierarchical nature of the data and to avoid biased associations.

\section{Fixed effects (measures of associations)}

Table 2 presents the fixed effects for individual and community-level factors. The fixed effects presented in model 2 show the associations between HPV vaccination and individual-level factors prior to consideration of community-level covariates. The fixed effects presented in model 3 indicate the associations between HPV vaccination and both individual and community-level factors. Subsequent consideration of both individual and community-level characteristics in model 3 indicated that a number of fixed effects (age, school attendance, being; a Foreigner, Iteso, Munyoro, Karamajong, Musoga and other tribe) steadily maintained their significance after adding level two fixed effects (community level factors). The variables for being an Iteso and having 9 or more members living in a household also remained statistically significant after controlling for level two fixed effects. The analysis of only individual-level factors, showed that child's age, school attendance, ethnicity, and size of family were significantly associated with HPV vaccination; the intra-class correlation coefficient (ICC) showed that 54\% of the variance in $\mathrm{HPV}$ vaccination was due to common community characteristics (ICC $=0.54, p<0.0001)$.

In the final model (Table 2), we included both individual- and community level characteristics. The results show that odds of HPV vaccination were higher among girls attending school $(\mathrm{OR}=2.88$; 95\% CI 2.12-3.92) than those who were not attending school. In respect to age, odds of HPV vaccination were higher among girls age 11,13 , and 14 years with $\mathrm{OR}=1.30$; $95 \%$ CI $1.06-$ $1.61, \mathrm{OR}=1.40 ; 95 \% \mathrm{CI} 1.15-1.70$, and $\mathrm{OR}=1.41 ; 95 \%$ CI 1.14-1.75 respectively compared to girls aged 10 years. In relation to tribe, odds of HPV vaccination were higher among girls who were foreigners, Iteso, karamajong, Banyoro, Basoga, and other tribe with $\mathrm{OR}=3.33$; 95\% CI $1.72-6.45$, OR $=1.79 ; 95 \%$ CI $1.17-2.73$, OR = $3.84 ; 95 \%$ CI $1.57-9.43, \mathrm{OR}=1.54 ; 95 \%$ CI $1.06-2.23$, $\mathrm{OR}=2.15 ; 95 \%$ CI $1.41-3.28$, and $\mathrm{OR}=1.50 ; 95 \% \mathrm{CI}$ $1.12-2.01$ respectively compared to Baganda girls. Odds of HPV vaccination were lower among girls who were living in households with 9 or more members (OR = $0.81 ; 95 \%$ CI $0.69-0.95)$ compared to those who were living in households with 1 to 8 members. Odds of HPV vaccination were higher among girls who were living in communities with middle wealth quintile $(\mathrm{OR}=$; $95 \% \mathrm{CI}$ 1.01-1.69) compared to those who were living in communities with the poorest wealth quintile. 
Table 2 Associations between individual and community factors with HPV Vaccination

\begin{tabular}{lll}
\hline & $\begin{array}{l}\text { Model } 2 \text { including individual level } \\
\text { determinants }\end{array}$ & $\begin{array}{l}\text { Model } 3 \text { including individual and community } \\
\text { level determinants }\end{array}$ \\
\hline Fixed effect $(\mathrm{OR}, 95 \% \mathrm{Cl})$ &
\end{tabular}

Fixed effect (OR, 95\% Cl)

Individual-level determinants

Girl's age

10 (Ref)

11

12

13

14

School attendance status

No (Ref)

Yes

2.93

\section{Ethnicity}

Baganda (Ref)a

Foreigners

3.31

Luo

1.15

$(1.06-1.61)^{*}$

1.30

$(1.06-1.61)^{*}$

1.15

1.17

1.73

Iteso

Karamajong

3.66

Banyoro

1.52

Basoga

2.18

Other

1.48

Region

Western (Ref)

$\begin{array}{ll}\text { Central } & 0.97\end{array}$

Eastern

Karamoja

1.29

Northern

1.24

$(0.71-1.86)$

\section{Household characteristics}

Amount of media exposure

0 (Ref)

1

1.10

$\geq 2$

1.22

$(1.00-1.50)$

Sex of household head

Female (Ref)

Male

0.87

Number of members in the household

1-8 (Ref)

$\geq 9$

0.81

Relationship to household head

Daughter (Ref)

Other relationship

0.94

Mother in the household

No (Ref)
$(2.16-4.0)^{* * *}$

2.88

$(2.12-3.92)^{* * *}$

(0.94-1.40)

1.14

1.40

1.41

$(1.15-1.76)^{* *}$

$(1.71-6.42)^{* * *}$

3.33

1.18

1.21

(0.65-2.11)

$(1.13-2.64)^{*}$

$(1.49-8.97)^{* *}$

$(1.05-2.21)^{*}$

$(1.43-3.32)^{* * *}$

$(1.11-1.98)^{* *}$

(0.73-1.29)

1.00

0.82

1.36

1.31

(0.56-2.95)

$(0.77-2.00)$

(0.90-1.35)

1.03

1.12

$(0.75-1.01)$

0.87

(0.75-1.01)

(0.94-1.39)

$(1.15-1.70)^{* *}$

$(1.14-1.75)^{* *}$

$$
\begin{aligned}
& (1.72-6.45)^{* * *} \\
& (0.73-1.91) \\
& (0.67-2.18) \\
& (1.17-2.73)^{* *} \\
& (1.57-9.43)^{* *} \\
& (1.06-2.23)^{*} \\
& (1.41-3.28)^{* * *} \\
& (1.12-2.01)^{* *}
\end{aligned}
$$

(0.74-1.33)

$(0.59-1.14)$

(0.59-3.14)

$(0.81-2.12)$

(0.83-1.28)

(0.87-1.41)

$(0.69-0.96)^{*}$

$(0.69-0.95)^{* *}$

(0.75-1.18)

0.94

(0.75-1.18) 
Table 2 Associations between individual and community factors with HPV Vaccination (Continued)

\begin{tabular}{|c|c|c|c|c|}
\hline \multirow[b]{2}{*}{ Yes } & \multicolumn{2}{|c|}{$\begin{array}{l}\text { Model } 2 \text { including individual level } \\
\text { determinants }\end{array}$} & \multicolumn{2}{|c|}{$\begin{array}{l}\text { Model } 3 \text { including individual and community } \\
\text { level determinants }\end{array}$} \\
\hline & 1.16 & $(0.94-1.44)$ & 1.17 & $(0.94-1.46)$ \\
\hline \multicolumn{5}{|c|}{ Community level factors } \\
\hline \multicolumn{5}{|c|}{ Type of residence } \\
\hline \multicolumn{5}{|c|}{ Rural (Ref) } \\
\hline Urban & & & 0.92 & $(0.72-1.17)$ \\
\hline \multicolumn{5}{|c|}{ Wealth index } \\
\hline \multicolumn{5}{|c|}{ Poorest (Ref) } \\
\hline Poorer & & & 1.11 & $(0.88-1.40)$ \\
\hline Middle & & & 1.31 & $(1.01-1.69)^{*}$ \\
\hline Rich & & & 1.22 & $(0.93-1.59)$ \\
\hline
\end{tabular}

\section{Discussion}

According to the study findings, uptake of the HPV vaccine among Ugandan girls aged 10 to 14 years was low (22\%). Although $\mathrm{MOH}$ had committed itself to achieve $80 \%$ HPV vaccine coverage by 2015 [12], one year before the survey [28]. These findings are close to the findings of a cross sectional study from northern Uganda [19]. Uganda's HPV vaccine coverage is lower than that of Rwanda (93.2\%) [38]. This low HPV vaccine coverage in Uganda could be associated with negative attitudes towards the vaccine [19, 39], limitations associated with the school based HPV vaccine delivery strategy $[13,17,40,41]$, and social cultural factors [41].

This study established the impact of contextual factors besides individual characteristics on HPV vaccination. Our findings established that the likelihood of HPV vaccination was not solely shaped by individual characteristics, but also communities where these girls were residing. Both community and individual-level factors were significantly associated with HPV vaccination. The study results found a significant negative association of socioeconomic deprivation of communities (rural areas with high proportion of poor people) with HPV vaccination. The strength of deprivation is determined by those two elements of socioeconomic disadvantages though they don't coexist together in similar proportions. There is scanty evidence in LMICs regarding the relationship between community level characteristics and HPV vaccination yet findings indicate that community level characteristics strongly predict health care utilization [21, 30-33]. The plausible explanation for this association is that people dwelling in the same community with socioeconomic disadvantages always have similar health care utilization (HPV vaccination) behaviors. People sharing community socioeconomic disadvantages tend to have challenges in accessing health care services, education and appreciating the significance of health care services. Community factors will mediate through individual level factors to influence health care utilization (HPV vaccination).

Our study indicate that older girls were more likely to be vaccinated than their one year younger counter parts. These findings are in consonance with earlier studies $[21,23,42]$. However, our findings are not supported by studies conducted elsewhere; both the oldest and the youngest age categories were found to have lower likelihood of HPV vaccination in the Netherlands [43]. This age effect may be attributed to an increased acceptance of the vaccine by the parents among their older daughters [44]. Another probable reason is procrastination: With HPV vaccine, girls have a long time lag (9-14 years) of eligibility for vaccination [12]. Girls might be reluctant to vaccinate at the lowest eligibility age. Finally, the sensitization posters or messages by which girls were informed about their eligibility (9-14 years) for HPV vaccine may have had a procrastination effect on vaccination initiation. This is consistent with previous research in which patient reminder and recall systems have been established to affect vaccination behavior [45].

The results of this study indicate that School attendance status was positively associated with HPV status. These findings are consistent with prior studies $[19,22]$. The plausible explanation for this association is the implementation of the school based HPV vaccine delivery strategy without special effort to reach out of school girls [20, 22, 25].

The current study found that ethnicity was significantly associated with HPV vaccination. This finding is similar to previous studies [21, 23, 25, 43]. The probable reason for this association is that individuals belonging 
to a social group with low uptake of vaccination have a higher chance to come across damaging beliefs, norms and emulate behavior from their peers. Another important finding was that medium social economic status was positively associated with HPV vaccination. The likelihood of having already been vaccinated was found among girls from middle wealth quintile settings although vaccination was free of charge for all girls. Such association between socio-economic status and adolescent vaccination has been found in other studies $[23,25,43,46]$. The probable explanation for this association is that HPV vaccine was rolled out nationwide in 2015 [18] one year before the survey [28] making it relatively new. Adoption of new positive health behaviors has been associated with Social Economic Status (SES) [47]. People with low SES are likely to adopt a new positive health behavior last because they base their decisions on what happened in the past, change behavior a long time after changes in their awareness and knowledge, suspicious of new interventions, take more time to convince and often poor economic position makes them very cautious [47]. However, the current findings are not consistent with some previous findings. Socioeconomic status was found not to be significantly associated with HPV Vaccination [22].

\section{Study limitations}

Notwithstanding the strength of this study, there were some limitations with the data. Our study was based on cross-sectional and secondary data. The dataset had no variables on mother's characteristics to facilitate better assessment of mother's characteristics. The dataset had no information for 9 year old girls to facilitate better assessment of vaccination coverage among girls age 9 years. Second, we combined individual responses to generate our measures at community level. It is therefore difficult to ascertain whether some girls were not classified into wrong administratively demarcated boundaries (clusters). The use of hierarchical regression models require aggregating individual responses to community level assuming that the groups are homogenous. This has potential consequences on the interpretation of results because associations at aggregated levels may not directly apply to individuals but to the group of individuals with in a given area. Nevertheless, the current study points to important programmatic areas of intervention for promoting HPV vaccination in Uganda.

\section{Conclusion}

This study considered countrywide representative data on HPV vaccination for the 2016 Uganda demographic and health survey. The results of the study established low HPV vaccine coverage in Uganda. Both community (community socioeconomic disadvantage) and individual (school attendance status, age of girls, ethnicity, and amount of media exposure) level factors were found to be significantly associated with HPV vaccination. Other countries in the region with organized school-based programmes have had much higher uptake rates. If higher vaccination rates are to be achieved in Uganda, both individual and community level factors responsible for variation in HPV vaccination should be addressed. System-wide interventions should be implemented to increase vaccine coverage in Uganda. Our findings point to the need for universal basic education, creation of job opportunities, and poverty alleviation. Our findings further suggest that effort should be directed at women and rural affirmative interventions to narrow gender and type of residence inequality gaps respectively. These are vital interventions that can be implemented at community level to mitigate the effects of community socioeconomic disadvantages. Variation in HPV vaccination among different ethnic groups indicate that communication on HPV vaccine should be tailored to ethnic communities.

\section{Abbreviations \\ Cl: Confidence interval; FDA: Food and Drug Administration; HPV: Human papillomavirus; $\mathrm{MOH}$ : Ministry of Health; OR: Odds ratio; SDGs: Sustainable Development Goals; SES: Socio-economic status; UBOS: Uganda Bureau of Statistics}

\section{Acknowledgements}

The authors recognize the review comments from Dr Barclay Kieron Research Fellow of Labolatory of Population Health at Max Planck Institute for Demographic Research, Rostock, Germany.The authors are grateful to Measures DHS for permitting us to explore the UDHS dataset. The authors also give thanks to Germany Academic Exchange Service (DAAD) for their support.

\section{Authors' contributions}

IA conceived, designed, wrote, and analyzed data. BK, AJ, and MM conceived, read, and reviewed the manuscript. All authors read and approved the manuscript.

\section{Author's information}

IA is an Assistant Lecturer at Department of Sociology and Social Administration, Faculty of Arts and Social Sciences, Kyambogo University, Kampala, Uganda. IA is a PhD student at the Department of Population Studies, School of Statistics and Planning, College of Business and Management Sciences, Makerere University, Kampala, Uganda. IA holds Masters in Population and reproductive Health (Makerere University). His research interests are maternal and child health.

MM is a Lecturer at the Department of Population Studies, School of Statistics and Planning, College of Business and Management Sciences, Makerere University, Kampala, Uganda.

JA is a Lecturer at the Department of Statistics and Planning, School of Statistics and Planning, College of Business and Management Sciences, Makerere University, Kampala, Uganda.

BK is an Associate Professor at the Department of Population Studies, School of Statistics and Planning, College of Business and Management Sciences, Makerere University, Kampala, Uganda.

\section{Funding}

None.

\section{Availability of data and materials}

Data are from the Demographic and Health Survey. The dataset is open to qualified researchers free of charge. To request access to the dataset, please apply at http://dhsprogram.com/data/Access-Instructions.cfm. 


\section{Ethics approval and consent to participate}

All data were obtained from the 2016 Uganda Demographic and Health Survey (UDHS). Written informed consent was got from each respondent prior to the interviews. Procedures and questionnaires for standard DHS surveys have been reviewed and approved by the ICF International Institutional Review Board (IRB). We obtained approval to use the data from the DHS repository (http://dhsprogram.com/data/available-datasets.cfm).

\section{Consent for publication}

Not applicable.

\section{Competing interests}

The authors declare that they have no competing interests.

Received: 31 January 2020 Accepted: 6 July 2020

\section{Published online: 13 July 2020}

\section{References}

1. Bray F, Ferlay J, Soerjomataram I, Siegel RL, Torre LA JA. Global Cancer Statistics 2018: GLOBOCAN Estimates of Incidence and Mortality Worldwide for 36 Cancers in 185 Countries. Ca cancer j clin [Internet]. 2018;00(00):1-31. Available from: cacancerjournal.com.

2. IARC. World Cancer Report 2020: International Agency for Research on Cancer, 150 cours Albert Thomas, 69372 Lyon Cedex 08, France; 2020.

3. WHO. Global Vaccine Action Plan 2011-2020: World Health Organization 2013.

4. UICC. World Cancer Declaration 2013:Union for International Cancer Control. 2013;

5. UN. Transforming our world: the 2030 agenda for sustainable development: United Nations. In 2015. Available from: sustainabledevelopment.un.org.

6. IARC. Cervical Cancer Estimated Incidence, Mortality and Prevalence Worldwide in 2012: GLOBOCAN 2012. 2013; Available from: https://gco.iarc. $\mathrm{fr} /$ today/data/pdf/fact-sheets/cancers/cancer-fact-sheets-16.pdf.

7. Bruni L, Albero G, Serrano B, Mena M, Gómez D, Muñoz J, Bosch FX de SS. Human papillomavirus and related diseases in Africa: summary report. ICO/ IARC Information Centre on HPV and Cancer (HPV Information Centre). 17 June 2019:2019.

8. Wabinga HR, Parkin DM NS. Kampala Cancer Registry report For the period 2007-2009: Kampala, Uganda, August 2012 [Internet]. 2012. Available from: http://www.afcrn.org/membership/81-kampala-uganda.

9. WHO. Country cancer profiles, Uganda: World Health Organisation. 2014 Available from: http://www.who.int/cancer/country-profiles/uga_en.pdf.

10. Finocchario-Kessler S, Wexler C, Maloba M, Mabachi N, Ndikum-Moffor F BE. Cervical cancer prevention and treatment research in Africa: a systematic review from a public health perspective. BMC Womens Health [Internet]. 2016;29(16):1-25. Available from: http://www.ncbi.nlm.nih.gov/pubmed/ 27259656\%5Cnhttp://www.pubmedcentral.nih.gov/articlerender.fcgi?artid= PMC4893293.

11. WHO. WHO guidance note: comprehensive cervical cancer prevention and control: a healthier future for girls and women: World Health Organisation. 2013; Available from: www.who.int.

12. $\mathrm{MOH}$. Strategic plan for cervical cancer prevention and control in Uganda 2010-2014. Kampala, Uganda: Ministry of Health. 2010;

13. Hidle A, Gwati G, Abimbola T, Pallas SW, Hyde T, Petu A, McFarland DMP. Cost of a human papillomavirus vaccination project, Zimbabwe. Bull World Heal Organ. 2018;96:834-42.

14. Ladner J, Besson M, Hampshire R, Tapert L, Chirenje M SJ. Assessment of eight HPV vaccination programs implemented in lowest income countries. BMC Public Health [Internet]. 2012;370(12):1-8. Available from: www. biomedcentral.com/1471-2458/12/370.

15. PATH. HPV vaccination in Africa. Lessons learned from a pilot program in Uganda: Program for Appropriate Technology in Health, Child Health and Development Centre (CHDC), and the Uganda National Expanded Program on Immunization. 2011; Available from: www.path.org/cervicalcancer.

16. Munoz N, Bosch FX, de-Sanjose S, Herrero R, Castellsague X, Shah KV, Snijders JF ML. Epidemiologic Classification of Human Papillomavirus Types Associated with Cervical Cancer: the International Agency for Research on Cancer Multicenter Cervical Cancer Study Group. N Engl J Med [Internet]. 2013;1-10. Available from: www.nejm.org.

17. PATH. Shaping a Strategy to Introduce HPV Vaccines in Uganda. Formative Research Results from the HPV Vaccines: Evidence for Impact Project:
Program for Appropriate Technology in Health. 2009; Available from: www. path.org/cervicalcancer.

18. WHO. Uganda launches Human Papillomavirus Vaccine [Internet]. 2015. Available from: https://www.afro.who.int/news/uganda-launches-

19. Kisaakye E, Namakula J, Kihembo C, Kisakye A, Nsubuga P BJ. Level and factors associated with uptake of human papillomavirus infection vaccine among female adolescents in Lira District, Uganda. Pan African Med Journal [Internet]. 2018; Available from: http://www.panafrican-med-journal.com/ content/article/31/184/full/.

20. Alberts CJ, Der-Loeff MF, Hazeveld Y, De-Melker HE, Der-Wal MF, Nielen A, Fakiri FE, Prins MPT. A longitudinal study on determinants of HPV vaccination uptake in parents/guardians from different ethnic backgrounds in Amsterdam, the Netherlands. BMC Public Health. 2017;220(17):1-12.

21. Lefevere $E$, Hens N, De-Smet F DP. Dynamics of HPV vaccination initiation in Flanders (Belgium) 2007-2009: a Cox regression model. BMC Public Health [Internet]. 2011;470(11). Available from: http://www.biomedcentral.com/14 71-2458/11/470.

22. Gallagher KE, Kadokura E, Eckert LO, Miyake S, Mounier-Jack S, Aldea M, Ross DA W-JD. Factors influencing completion of multidose vaccine schedules in adolescents: a systematic review. BMC Public Health. 2016;172(16).

23. Schülein S, Taylor KJ, König J, Claus M, Blettner M KS. Factors influencing uptake of HPV vaccination among girls in Germany. BMC Public Health. 2016:996(16).

24. Gallagher KE, Kadokura E, Eckert LO, Miyake S, Aldea M, Ross DA. Factors influencing completion of multi- dose vaccine schedules in adolescents : a systematic review. BMC Public Health [Internet]. 2016; Available from: https://doi.org/10.1186/s12889-016-2845-z.

25. Kumar VMWD. Explaining variation in the uptake of HPV vaccination in England. BMC Public Health [Internet]. 2011;172(11):1-7 Available from: http://www.biomedcentral.com/1471-2458/11/172.

26. Vamos CA, Vázquez-Otero C, Kline N. Lockhart EA. Proctor S, Meade CD DE. Multi-level determinants to HPV vaccination among Hispanic farmworker families in Florida. Ethn Health: Wells K; 2018.

27. UBOS. Demographic and Health surveys data sets [Internet]. 2016 [cited 2019 Oct 21]. Available from: https://dhsprogram.com/data/dataset_admin/ index.cfm.

28. UBOS. Uganda demographic and health survey 2016. Kampala: Uganda and Rockville, Maryland, USA; 2018. Available from: https://dhsprogram.com/ pubs/pdf/FR333/FR333.pdf.

29. UBOS. National Population and housing census 2014- Main report, Kampala. Uganda Bureau of Statistics: Uganda; 2016. Available from: https:// www.ubos.org/wp-content/uploads/publications/03_20182014_National_ Census_Main_Report.pdf.

30. Andersen R NJ. Societal and Individual Determinants of Medical Care Utilization in the United States. Heal Soc. 1973;(51):95-124.

31. Bandura A. Social cognitive theory, In R. Vasta (Ed.), Annals of child development. Six theories of child development. Greenwich, CT: : JAl Press;; 1989. 1-60 p.

32. Tiruneh FN, Chuang K, Austin P, Ntenda MCY. Individual-level and community-level determinants of cervical cancer screening among Kenyan women: a multilevel analysis of a Nationwide survey. BMC Womens Health. 2017;109(17):1-14.

33. Kayode GA, Ansah E, Agyepong IA, Amoakoh-Coleman M, Grobbee DE KGK. Individual and community determinants of neonatal mortality in Ghana: A multilevel analysis. BMC Pregnancy Childbirth [Internet]. 2014;165(14). Available from: http://www.biomedcentral.com/1471-2393/14/165.

34. Gelman AHJ. Data analysis using regression and multilevel/hierarchical models. Cambridge University Press. 2006.

35. Browne WJ, Subramanian SV, Jones KGH. Variance partitioning in multilevel logistic models that exhibit overdispersion. R Stat Soc. 2005;168(3):599-613.

36. Akaike H. A New Look at the Statistical Model Identification. In 1974. p. 716-724.

37. Schmidt CKT. When to use the odds ratio or the relative risk? Int J Public Heal. 2008;53:165-7.

38. Binagwaho A, Wagner CM, Gatera M, Karema C, Nutt TNF. Achieving high coverage in Rwanda's national human papillomavirus vaccination programme. Bull World Heal Organ. 2012;90:623-8.

39. Nickel B, Dodd RH, Turner RM, Waller J, Marlow L, Zimet G, Ostini R MK. Factors associated with the human papillomavirus (HPV) vaccination across three countries following vaccination introduction. Prev Med Reports. 2017; $169-76$.

40. Watson-Jones D, Baisley K, Ponsiano R, Lemme F, Remes P, Ross D, Kapiga S, Mayaud P, De-Sanjosé S, Wight D, Changalucha JHR. Human papillomavirus 
vaccination in Tanzanian schoolgirls: cluster-randomized trial comparing 2 vaccine-delivery strategies. J Infect Dis. 2012;206:678-86.

41. Bingham A, Drake JK LD. Sociocultural Issues in the Introduction of Human Papillomavirus Vaccine in Low-Resource Settings. Arch Pediatr Adolesc med [Internet]. 2009;163(5):1-7. Available from: \%0Awww.archpediatrics.com\%0A.

42. Dempsey A, Cohn L, Dalton VRM. Patient and clinic factors associated with adolescent human papillomavirus vaccine utilization within a universitybased health system. Vaccine. 2010;28(4):989-95.

43. Marc R, Alies VL, Jan VDK, Laura RHD. Determinants for HPV vaccine uptake in the Netherlands: a multilevel study. Vaccine. 2010;28:2070-5.

44. Dempsey A, Zimet G, Davis RKL. Factors that are associated with parental acceptance of human papillomavirus vaccines: a randomized intervention study of written information about HPV. Pediatrics. 2006;117(5):1486-93.

45. Szilagyi P, Bordley C, Vann J, Chelminski A, Kraus R, LE Margolis PR. Effect of patient reminder/recall interventions on immunization rates. J Am Med Assoc. 2000;284(14):1-9.

46. Lefevere $\mathrm{E}$, Hens N, Smet F De, Damme P Van. Dynamics of HPV vaccination initiation in Flanders ( Belgium ) 2007-2009: a Cox regression model. 2011;.

47. Rogers EM. Diffussion of Innovations. Third Edit. 866 Third Avenue, New York, N. Y. 10022: The Free Press; 1983. 1-236 p.

\section{Publisher's Note}

Springer Nature remains neutral with regard to jurisdictional claims in published maps and institutional affiliations.

Ready to submit your research? Choose BMC and benefit from:

- fast, convenient online submission

- thorough peer review by experienced researchers in your field

- rapid publication on acceptance

- support for research data, including large and complex data types

- gold Open Access which fosters wider collaboration and increased citations

- maximum visibility for your research: over $100 \mathrm{M}$ website views per year

At BMC, research is always in progress.

Learn more biomedcentral.com/submissions 